\title{
A inserção profissional sob o olhar dos professores iniciantes: possibilidades de implantação de políticas públicas
}

\author{
The professional insertion under the begginners teachers view: public policies \\ implementation possibilities
}

\author{
La mirada profesional de profesores principiantes: posibilidades de \\ implantación de políticas públicas
}

\author{
ANDREIA DiAs PirEs FERREIRA* \\ ANA MARIA GIMENES CORREA CALIL** \\ JOSEANE AMÂNCIO PINTO*** \\ MARIANA ARANHA DE SOUZA****
}

\begin{abstract}
RESUMO
O início da carreira é um período complexo, no qual o professor inicia a construção de sua identidade profissional. Esse processo de inserção profissional docente requer muitos cuidados no sentido de suprir e atender às necessidades características dessa etapa. Este estudo, de abordagem quali-quantitativa, procurou compreender como 157 professores iniciantes de Educação Infantil e Ensino Fundamental de uma rede municipal de ensino do interior paulista percebem as ações realizadas nesse processo, bem como suas necessidades durante esse período. Os resultados possibilitaram identificar que as experiências vividas por eles se converteram em sugestões de medidas que podem contribuir para o aprimoramento da prática docente e para a implementação de políticas públicas para a inserção profissional dos docentes iniciantes.
\end{abstract}

Palavras-chave: Professor iniciante. Inserção profissional. Políticas públicas.

\begin{abstract}
The beginning of the career is a complex period in which the teacher begins to build his professional identity. The process of professional insertion requires a lot of care in order to meet and meet the needs of this stage. This qualitative and quantitative study sought to understand how 157 beginning teachers of Early Childhood Education and Elementary School in a municipal school network in the interior of São Paulo perceive the actions taken in the process of professional insertion as well as their needs during this period. The results made it possible to identify that their experiences have become suggestions for measures that can contribute to the improvement of teaching practice and the implementation of public policies for the professional insertion of beginning teachers.

Keywords: Beginning teacher. Professional insertion. Public police.

\section{RESUMEN}

El comienzo de su carrera es un período complejo en el que el maestro inicia la construcción de su identidad profesional. El proceso de inserción profesional de la enseñanza requiere un gran cuidado con el fin de suministrar y satisfacer las necesidades características de esta etapa. Este estudio de enfoque cualitativo y cuantitativo, trató de comprender cómo a partir de 157 maestros de jardín de infancia y la escuela primaria en una escuela municipal en Sao Paulo perciben las acciones llevadas a cabo en el proceso de inserción profesional, así como sus necesidades durante este período. Los resultados permitieron identificar las experiencias que se han convertido en propuestas de medidas que pueden contribuir a la mejora de la práctica docente y la implementación de políticas públicas para la integración profesional de los profesores noveles.

Palabras clave: Principiante maestro. Inserción profesional. Políticas públicas.
\end{abstract}

* Mestre em Educação pela Universidade de Taubaté. Pedagoga pela Universidade do Vale do Paraíba - UNIVAP. Professora da Rede Municipal de Ensino de São José dos Campos. E-mail: < deia.pires@hotmail.com>.

** Doutora em Educação (Psicologia da Educação) pela Pontifícia Universidade Católica de São Paulo. Mestre em Educação (Psicologia da Educação) pela Pontifícia Universidade Católica de São Paulo. Pedagoga e Economista pela Universidade de Taubaté. E-mail: <ana.calil@unitau.com.br>.

*** Mestre em Educação pela Universidade de Taubaté. Pedagoga pela Universidade do Vale do Paraíba - UNIVAP. Professora da Rede Municipal de Ensino de São José dos Campos. E-mail: <joseane.amancio@hotmail.com>.

**** Doutora em Educação (Currículo) pela Pontifícia Universidade Católica de São Paulo. Mestre em Educação (Currículo) pela Pontifícia Universidade Católica de São Paulo. Graduada em Pedagogia pela Faculdade Maria Augusta Ribeiro Daher. E-mail: <profa.maaranha@gmail.com>. 


\section{INTRODUÇÃO}

O início da carreira docente configura-se como um período complexo e de intensas aprendizagens e descobertas, já que o professor recém-formado, aqui denominado iniciante, adentra em um novo contexto escolar. Marcelo Garcia (1999, p. 113) caracteriza esse momento como "o período que abarca os primeiros anos, nos quais os professores fazem a transição de estudantes para professores", e acrescenta que é nele que o professor irá vivenciar grandes desafios, tensões, insegurança, medos e aprendizagens, necessários ao exercício da docência.

Para Huberman (1995), o desenvolvimento profissional da carreira docente pode ser considerado como um ciclo, constituído por cinco fases: (1) entrada; (2) estabilização; (3) diversificação; (4) serenidade; e (5) desinvestimento. Para o autor, essas fases não se constituem em etapas fixas, mas em um processo dinâmico e bem peculiar.

A primeira fase, denominada fase de entrada, é caracterizada por Huberman (1995) como um momento de tateamento, sobrevivência e descoberta, e corresponde aos três primeiros anos de docência. E a expressão "sobrevivência" traduz o que o autor denominou de "choque do real", ou seja, o momento em que o professor iniciante percebe a distância existente entre os ideais educacionais e a realidade encontrada no contexto da escola. Já a expressão "descoberta”, por sua vez, reflete o momento em que o professor iniciante vai descobrindo o que caracteriza a profissão e começa a se identificar com ela.

Posteriormente, o docente avança gradativamente para uma segunda fase: a estabilização. Para Huberman (1995), esse é o momento de consolidação do repertório pedagógico do professor e ocorre, aproximadamente, entre o quarto e o sexto ano de docência. Fase que se caracteriza pela tomada de consciência do professor de seu papel enquanto docente e, consequentemente, por sua afirmação perante os colegas mais experientes.

A terceira fase do ciclo de desenvolvimento profissional, e que compreende o período que abrange do sétimo ao $25^{\circ}$ ano de docência, é denominada por Huberman (1995) como a da diversificação ou ativismo. Para o autor, o professor, nessa fase, diversifica sua prática pedagógica, os materiais didáticos utilizados, as formas de avaliação, o planejamento e, até mesmo, a forma de agrupar os alunos. É um período também conhecido como ativismo ou questionamento, pois, de uma maneira geral, os professores estão mais motivados, dinâmicos, empenhados e participativos nas comissões e nos conselhos da unidade escolar em que atuam.

A quarta fase, da serenidade, compreende o período de 25 a 35 anos de carreira. O termo "serenidade" expressa o sentimento do professor nesse momento da carreira por sentir-se mais seguro e não vulnerável à avaliação dos outros professores. Por isso, também é conhecido como um período de "distanciamento afetivo e conservadorismo". Segundo Huberman (1995), os professores nessa fase acreditam que não precisam provar mais nada a ninguém e que a sala de aula é o espaço que julgam dominar, o que faz a sensação de confiança e de serenidade aumentar.

Por fim, há uma última fase, o desinvestimento, que corresponde ao período de 35 a 40 anos de profissão e que se dá, normalmente, no final da carreira. Huberman (1995) afirma que, nesse período, o professor tende a sentir-se liberto e, por isso, passa a dedicar mais tempo a si próprio, recuando das atividades que envolvem a profissão.

Marcelo Garcia (1999) acredita que as sensações experimentadas no início da carreira podem voltar a ocorrer sempre que há mudança de escola ou quando o professor transita de uma modalidade de ensino para outra. Tais sensações, de acordo com o autor, tendem a ser acometidas de acordo com a trajetória profissional do professor, como as experiências que ele atravessou com a organização da instituição que lecionou, como foi acolhido pela equipe, as questões sociais e políticas enfrentadas naquele determinado momento histórico e os próprios conhecimentos teóricos que possui.

Destaca Perrenoud (2001) que o professor iniciante se sente um estrangeiro num país desconhecido, ao entrar na sala de aula pela primeira vez, principalmente pela diversidade de atribuições que precisa gerir, como manter a disciplina da sala, dominar os conteúdos as serem ensinados, ensinar, relacionar-se com os alunos e com suas famílias, zelar pela parte burocrática, além de vários e novos papéis, o que o faz, muitas vezes, agir na imprevisibilidade, na urgência e na emergência.

Papi e Martins (2010, p.44) apontam ainda que é "no período de iniciação profissional que o professor se defrontará com a realidade que está posta e com as contradições que nem sempre estará apto a superar". O distanciamento entre a profissão idealizada e a realidade vivida caracteriza esse momento como bastante peculiar para o professor iniciante, pois muito do que ele idealizou não condiz com o contexto escolar. Para as autoras, o professor iniciante não se sente preparado para enfrentar a realidade e nem para superar os desafios da carreira, por isso apresenta insegurança, falta de confiança em si mesmo, dificuldade em exercer o ofício docente e em ensinar os alunos. Marcelo Garcia (1999) afirma que, muitas vezes, o sonho do início da docência pode acabar se transformando em frustração.

Por isso, Marcelo Garcia e Vaillant (2009) afirmam que aprender a ensinar não é tarefa fácil e alertam que 
algumas competências já deveriam ser aprendidas na formação inicial, como o conhecimento didático e teórico e o conhecimento dos conteúdos a serem ministrados. Ressaltam ainda que outras competências são aprendidas somente na prática, como conhecer os alunos e o contexto escolar, apropriar-se do currículo e continuar desenvolvendo sua identidade profissional. Para Marcelo Garcia (1999),

[...] o ajuste dos professores a sua nova profissão depende $[\ldots]$ das experiências biográficas anteriores, dos seus modelos de imitação anteriores, da organização burocrática em que se encontra inserido desde o primeiro momento da sua vida profissional, dos colegas e do meio em que iniciou a sua carreira docente (MARCELO GARCIA, 1999, p. 118).

O ajuste que o autor menciona reafirma a constatação de que a inserção do docente iniciante na profissão é um processo que precisa ser planejado de forma sistemática e intencional, segundo afirma Freire (2001):

ninguém começa a ser educador numa certa terçafeira às quatro da tarde. Ninguém nasce educador ou marcado para ser educador. A gente se faz educador, a gente se forma, como educador, permanentemente, na prática e na reflexão sobre a prática (FREIRE, 2001, p. 59).

Isso explica a necessidade de se ter um cuidado especial no processo de inserção dos professores iniciantes nas escolas, de acolhê-los de forma que se reconheçam seus anseios e necessidades. Se a forma como ocorre essa inserção não for condizente com as dificuldades do professor iniciante, esse momento poderá causar sofrimento e desconforto, e, consequentemente, ocasionar o desejo de abandonar a profissão.

Daí a necessidade de dar voz aos professores iniciantes, a fim de conhecer, sob a perspectiva deles, o que sentem e percebem como necessário para suprir as particularidades do início da carreira. No entanto, é preciso ressaltar que a aprendizagem da docência ocorre ao longo de toda a sua trajetória e que as vivências dessa fase inicial também são fundamentais para a construção do profissional que ele será ao longo de toda a sua carreira.

\section{Percurso metodológico}

A fim de compreender as ações necessárias ao processo de inserção do profissional docente, no que concerne aos sentimentos, desafios e dificuldades enfrentadas, este artigo procura analisar dados de duas pesquisas realizadas com 157 professores iniciantes, sendo 89 na Educação Infantil e 68 no Ensino Fundamental I de uma mesma rede municipal de ensino do interior paulista. O critério para a participação dos docentes na pesquisa foi que tivessem até três anos de ingresso na rede municipal. Verificou-se que os professores iniciantes do Ensino Fundamental I estavam em 15 escolas, enquanto os professores iniciantes da Educação Infantil estavam em 52 escolas. Os professores do Ensino Fundamental são denominados de PEF e os professores de Educação Infantil, PEI, seguidos de um número.

De abordagem quali-quantitativa, as pesquisas procuraram analisar as respostas dos docentes a um questionário com questões fechadas e abertas, a respeito de sua percepção sobre inserção profissional em uma rede de ensino que não oferece um programa especial de acolhimento, além de suas sugestões sobre esse tema.

Os dados quantitativos, advindos das questões fechadas, foram tabulados pelo programa Sphinx Léxica e analisados, em consonância com os dados das questões abertas, a partir de uma perspectiva qualitativa, por levar em consideração a subjetividade do sujeito e a sua vivência, que não podem ser traduzidas apenas em números.

Essa perspectiva mista de métodos permitiu que se compreendessem os aspectos mais recorrentes das falas dos professores, a partir de uma análise interpretativa, fundamentada nas relações que os dados estabelecem entre si. Esse movimento, como afirma Chizzotti (2010),

[...] procura compreender os processos e a interpretação do dia-a-dia que dão sentido às ações humanas, ou seja, o mundo da vida cotidiana, das rotinas habituais e mecânicas, que vão estruturando a vida social dos indivíduos. Cabe aos pesquisadores identificar e descrever as práticas e os significados sociais (CHIZZOTTI, 2010, p. 104).

Este trabalho tem como objetivos identificar as ações realizadas no processo de inserção profissional docente, bem como analisar quais ações os professores percebem como necessárias para o início da carreira diante das experiências que viveram, a fim de contribuir para a discussão sobre a implementação de políticas públicas que considerem o docente que se inicia na profissão.

\section{O INÍCIO DA CARREIRA DOCENTE: ENTRE SENTIMENTOS E IMPRESSÕES}

A fim de conhecer e analisar como ocorreu o processo de inserção na rede municipal para os professores, questionou-se como foi para eles o início da carreira em uma rede de ensino que não possui um programa institucional para a inserção de docentes iniciantes. Os professores afirmaram que vivenciaram: (a) momentos de descoberta e encantamento com a profissão; e 
(b) momentos de "choque com o real" e de consequente sobrevivência da profissão.

As respostas a seguir retratam a fase da "descoberta", que Huberman $(1995$, p.39) diz_ser o "entusiasmo inicial, a exaltação por estar, finalmente, em situação de responsabilidade (ter a sua sala de aula, os seus alunos, o seu programa), por sentir-se num determinado corpo profissional". Os professores apontaram a tranquilidade e a satisfação pessoal e profissional que sentiram no momento do seu ingresso na profissão:

"Foi tranquila, pois tive a sorte de estar em uma boa escola com uma ótima turma." (PEF 19)

"Foi tranquila, pois a equipe escolar apoiou meu trabalho e sempre se mostrou disposta a esclarecer e ajudar a resolver dúvidas e problemas.” (PEF 28)

"Foi tranquila, fui bem recebida e orientada." (PEF 34)

Papi e Martins (2010) ressaltam que o encantamento inicial com a profissão pode ocorrer pelo fato de os docentes terem encontrado boas condições de trabalho, boas relações com os colegas e apoio de funcionários e gestores da escola nessa etapa do desenvolvimento profissional.

Por outro lado, os docentes iniciantes evidenciaram as dificuldades e os desafios próprios desse momento, ao mesmo tempo que apontaram o apoio dos colegas de trabalho como fundamental para a superação de tais problemas:

"Foi desafiador, porém muito gratificante e de muito aprendizado." (PEF 5)

"Foram muitas emoções, desde a alegria de ter sido efetivada no cargo, ao medo de não conseguir dar conta da sala de aula, de não ser aceita pelas crianças e colegas." (PEI 5)

"No final da aula, eu tinha a certeza de que eu teria muito que aprender, que me dedicar, mas que de lá eu não queria mais sair!" (PEI 16)

"Minha expectativa era ser bem recebida, fazer parte do grupo, ser acolhida pelos colegas de trabalho [...]. Foi um momento de conhecimento, de cuidar, cantar, brincar." (PEI 42)

Em contrapartida, alguns professores sentiram dificuldade ao iniciarem a carreira docente pelas cobranças, pressão e responsabilidade de assumir uma turma. Huberman (1995) denomina esse momento como período da "sobrevivência", cujas características são:

[...] o "choque do real", a confrontação inicial com a complexidade da situação profissional: o tatear constante, a preocupação consigo próprio ("Estou a me aguentar?"), a distância entre os ideais e as realidades quotidianas da sala de aula, a fragmentação do trabalho, a dificuldade em fazer face, simultaneamente, à relação pedagógica e à transmissão de conhecimentos, a oscilação entre relações demasiado íntimas e demasiado distantes, dificuldades com alunos que criam problemas, com material didático inadequado, etc... (HUBERMAN, 1995, p. 39).

Para o autor, esses sentimentos acabam por se transformar em insegurança e medo, conforme pode ser observado nas respostas a seguir:

"Foi difícil, tinha muitas dificuldades relacionadas à minha formação." (PEF 20)

"No início foi difícil, pois tudo era novo e eu precisei me aprofundar mais nos estudos para me adaptar à rede." (PEF 24)

"Senti muita insegurança." (PEF 35)

"Foi bastante confusa, várias informações e cobranças." (PEF 54)

"A escola de hoje, sua estrutura e até mesmo a formação do professor não estão acompanhando a evolução da criança." (PEI 17)

"Há distância entre teoria e prática." (PEI 61)

As respostas apresentadas acima revelam a frustação que esses professores sentiram ao perceberem a distância entre o que aprenderam na formação superior e a realidade que encontraram no contexto escolar. No período da sobrevivência, apontado por Huberman (1995), o docente se frustra muito ao descobrir a distância existente entre os seus sonhos enquanto estudante do curso de graduação e a realidade enfrentada como profissional, o que torna esse momento difícil e desanimador.

Papi e Martins (2010, p. 43) afirmam que "é no período de iniciação profissional que o professor se defrontará com a realidade que está posta e com contradições que nem sempre estará apto a superar. Seus conhecimentos profissionais são colocados em xeque". Isto revela que o processo de inserção profissional docente pode ser considerado como uma "caixa de surpresas", pois o professor nunca sabe o que o espera.

\section{SUPERAR OS DESAFIOS DA INSERÇÃO PROFISSIONAL DOCENTE: O QUE DIZEM OS PROFESSORES}

Dos professores respondentes de Educação Infantil, $79,7 \%$ apontaram que um fator que ajuda a superar as dificuldades do início da carreira e tornar esse momento mais tranquilo é receber o apoio dos colegas mais experientes, como pode ser verificado em alguns dos excertos a seguir: 
"As trocas de experiência entre os professores e as dicas da orientadora para enriquecimento do nosso trabalho." (PEI 82)

"Troca de experiências entre os pares acrescenta muito ao trabalho." (PEI 89)

"Os conteúdos nos apoiam em sala e as trocas entre as parceiras enriquecem o trabalho." (PEI 65)

"A discussão com os colegas enriqueceu o trabalho." (PEI 75)

"Para mim, foi muito boa, pois encontrei uma professora muito legal que me ajudou muito." (PEF 75)

"Foi tranquilo, recebi auxílio dos colegas quando precisei." (PEF 15)

"Na sala de quarto ano, em 2011, contei com a ajuda de colegas. Foi tranquilo." (PEF 29)

"Tranquilo, sempre quis muito desenvolver um bom trabalho e tive pessoas que me apoiaram." (PEF 40)

As respostas apresentadas por esses professores evidenciam o quanto é significativo e importante aprender com os colegas mais experientes, pois estes os ajudam a superar o medo, a insegurança e sanar as dúvidas. Lima (2006) chama essa prática de "rede de ajudas" e ressalta que a satisfação de poder aprender a docência com os pares contribui para a descoberta da profissão.

Para os professores, o apoio dos colegas surge como um ponto positivo, pois torna-se evidente que essas trocas de experiências são de suma importância na construção da identidade do professor e na aquisição dos saberes da prática.

\section{REPENSANDO POLÍTICAS PUBLICAS DE INSERÇÃO PROFISSIONAL A PARTIR DO OLHAR DOS PROFESSORES INICIANTES}

André (2015) afirma que é fundamental a implementação de uma política pública que apoie o professor iniciante por meio de projetos ou programas que favoreçam a formação específica para inserir os iniciantes profissionalmente, que seja diferente da inicial e continuada, principalmente por conta de suas peculiaridades. Uma possibilidade por ela apontada é estar atento para as políticas desenvolvidas em alguns municípios, de apoio aos professores iniciantes, para que possam ser adaptadas e ampliadas para outros locais, a fim de manter os profissionais do magistério na sua função, assegurando a qualidade de suas ações.

No Brasil, algumas iniciativas de políticas públicas para iniciantes têm despontado tanto em secretarias estaduais quanto em municipais. Entretanto, são poucas, e o assunto ainda requer discussão e mais iniciativas. No âmbito das secretarias estaduais, pode-se dizer que são ações formativas mais pontuais. Há os exemplos do estado do Espírito Santo, que promoveu um curso de formação de 60 horas aos candidatos a iniciantes e, somente depois do término do curso, estes foram submetidos à prova eliminatória; e o caso do estado do Ceará, que propôs um curso, em 2009, com cinco módulos em EaD (sobre Didática Geral e Administração Pública) aos ingressantes, ainda no estágio probatório (ANDRÉ, 2012).

$\mathrm{Na}$ esfera municipal, existem as iniciativas de Jundiaí/SP, em que os iniciantes tiveram 30 dias de formação, antes de entrarem em sala de aula, ministrada por especialistas de duas fundações contratadas. Os exemplos de políticas públicas com programas de formação específica aos iniciantes são os realizados nos municípios de Campo Grande/MS e Sobral/CE. Em Campo Grande, o programa se dá em cinco momentos: a chegada dos iniciantes na rede e as informações do funcionamento do sistema de ensino; o diagnóstico das principais necessidades dos professores; a formação in loco na escola; o acompanhamento do processo de ensino e aprendizagem; e a avaliação da aprendizagem dos alunos. O único programa institucionalizado e inserido na política de formação continuada do município é o de Sobral/ CE (ANDRÉ, 2012). Esse programa, específico para os iniciantes da rede, foi regulamentado pela Lei Municipal no 671, de 10 de abril de 2006. Trata-se de um programa de $200 \mathrm{~h} / \mathrm{a}$, compulsório e remunerado (corresponde a $25 \%$ do salário de 40 horas), pois é realizado fora do período de trabalho. Além de carga horária dos módulos dirigidos ao interesse dos professores iniciantes ministrado pela Esfapem (Escola de Formação e Aperfeiçoamento permanente do Magistério), os docentes contam com a participação no Programa Olhares, destinado à ampliação do universo cultural dos professores. Nesse município, os professores iniciantes frequentam tanto as formações específicas quanto as formações em exercício realizadas para todos os professores da rede.

Nas pesquisas que originaram este artigo, os professores iniciantes foram convidados a sugerir ações que poderiam auxiliar qualquer docente em início de carreira, considerando as experiências de "descoberta" e "sobrevivência" que tiveram em uma rede de ensino que não oferece formação específica para o ingresso do professor iniciante.

Dos professores de Ensino Fundamental, 25\% sugeriram a garantia de um momento de troca de experiências; $20,5 \%$, orientações sobre as regras da escola; $19,1 \%$, o apoio da equipe liderança e; $17,6 \%$, uma formação específica para os professores iniciantes. Dos professores de Educação Infantil, 47\% sugeriram acompanhamento da administração da escola; 89,7\%, cursos de formação continuada; e 99\%, espaço para troca de experiências com pares. 
Os excertos, a seguir, apresentam algumas das sugestões com relação à troca de experiências:

"Mais integração com os outros professores mais experientes." (PEF 10)

"Proporcionar momentos de experiência acolhendo os novos e parceria com os professores mais experientes." (PEF 11)

"Momentos para troca de experiência entre os pares." (PEF 26)

"Garantir a integração com professores do mesmo ano/ série." (PEF 30)

"Favorecer a troca de experiências, reflexões sobre a prática e a construção de novos saberes." (PEI 05)

"Troca de vivências." (PEI 33)

"O HTC é um momento para tudo e para debate das necessidades da classe que leciono." (PEI 88)

As ações apontadas pelos professores permitem inferir que as sugestõesrefletem o que sentiram falta no início de suas carreiras, além de corroborar o quanto valorizam e validam as trocas de experiências com os pares como uma fonte de aprendizagem da docência, como um saber prático. Nesse sentido, André (2015, p.36) afirma que "as tarefas de melhoria da escola têm de ser realizadas pelo coletivo, em um processo de interação, trocas e colaboração". Quando a escola trabalha no coletivo, oportunizando trocas, ocorrem melhorias em vários contextos: no processo de ensino e aprendizagem, na prática pedagógica, no clima organizacional, no relacionamento interpessoal e na própria profissão docente.

Considerando o que disseram os professores iniciantes, são propostas de discussão os seguintes elementos para se repensar políticas públicas de inserção profissional docente: (a) troca de experiências entre os docentes; (b) condições de trabalho; (c) acolhimento da equipe gestora; e (d) importância de programas de formação específica para os professores iniciantes.

\section{TROCA DE EXPERIÊNCIAS ENTRE OS DOCENTES}

A troca de experiências é priorizada e valorizada pelos iniciantes pesquisados como um fator importante para a inserção profissional e para a melhoria da prática docente. Os professores do Ensino Fundamental assinalaram os cursos de formação continuada, o espaço para troca de experiências com os colegas mais experientes e o acompanhamento da administração da escola como fatores importantes para esse período.

Os docentes deram ênfase aos processos que ocorrem durante os HTCs (Horários de Trabalho Coletivo):

\begin{abstract}
"Sempre aprendemos em HTC, com assuntos coerentes à prática." ( $\mathrm{PEI} 45)$

"Ótima, sempre aprendemos coisas novas e podemos sanar nossas dúvidas.” (PEI 21)

"Neste ano foi um começo e aprendi muito, principalmente nos HTCs." (PEI 56)

"As reflexões realizadas sobre teoria $\times$ prática contribuem para melhorias na sala de aula." (PEI 79)

"Colegas de trabalho que compartilharam suas experiências." (PEF 40)

"Receber dicas de colegas mais experientes, conhecer novas comunidades e diferentes profissionais." (PEF 53)

"A troca de experiência com professores antigos." (PEF 59)
\end{abstract}

Acredita-se que a criação e a garantia de um espaço de troca de experiências surge como uma ação para os ajudar no processo de aprendizagem da docência no início da carreira. Sobre isso, Nono (2011) ressalta que os professores veem na troca de experiências uma fonte de aprendizagem profissional, por isso reivindicam que esse espaço seja garantido a eles, como uma forma de reconhecer o valor do saber contruído na prática, espaço democrático, de fala e escuta, como desvelado por Freire (1997):

se, na verdade, o sonho que nos anima é democrático e solidário, não é falando aos outros, de cima para baixo, sobretudo, como se fôssemos os portadores da verdade a ser transmitida aos demais, que aprendemos a escutar, mas é escutando que aprendemos a falar com eles. Somente quem escuta pacientemente e criticamente o outro, fala com ele, mesmo que em certas condições precise de falar a ele (FREIRE, 1997, p. 127-128, grifos do autor).

\section{CONDIÇÕES DE TRABALHO}

Por sua vez, ao serem indagados sobre os fatores que poderiam contribuir para a melhoria da qualidade do trabalho, os professores iniciantes de Ensino Fundamental apontaram como importantes: reduzir o número de alunos por sala e receber melhor remuneração. Eles acreditam que com menos alunos por sala poderão distribuir melhor a atenção aos alunos, suprir as necessidades e dificuldades da turma, e assim, melhorar a qualidade do ensino oferecido.

O fator do aumento salarial também é visto pelos docentes como um ponto a ser melhorado, pois consideram que o professor bem remunerado poderá dedicar-se somente a uma unidade escolar. No caso de o professor não ser bem remunerado, pode ocasionar a necessidade de ter dupla jornada de trabalho e, consequentemente, ter 
excesso de trabalho, o que interfere no tempo de estudo e planejamento que o professor dispõe para preparar suas aulas, prejudicando seu desempenho profissional e a qualidade do ensino.

Os mesmos itens também foram apontados pelos

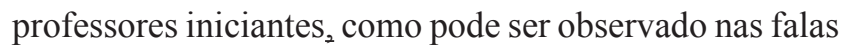
a seguir:

"O déficit de estrutura do sistema é oposto do que se espera encontrar na escola, uma vez que na faculdade se estuda teoria e não o que fazer com a turma superlotada para alfabetizar." (PEI 16)

"O professor iniciante tem baixo salário, se comparado com outros profissionais graduados e com o mesmo tempo de exercício de profissão." (PEI 42)

"Devido ao salário inicial e à falta de perspectiva de aumento significativo, à falta de estímulo ao estudo e aos problemas enfrentados no dia a dia da sala de aula e ainda à falta de respeito e desvalorização da carreira." (PEF 31)

"Sinto-me desvalorizada porque estudei muito e não sou recompensada financeiramente, e a prefeitura não me estimula a continuar estudando.” (PEF 50)

André (2015, p.37) adverte que "a melhoria da formação continuada é um fator importante no desenvolvimento profissional docente, mas, não o único. Fatores como salário, carreiras, estruturas [...] são igualmente importantes". Nesse sentido, falar sobre a melhoria da qualidade de ensino exige pensar, sobretudo, em políticas que considerem a melhoria das condições de trabalho, de salário e, consequentemente, repensar os planos de carreira.

\section{O ACOLHIMENTO DA EQUIPE GESTORA}

Outra ação sugerida pelos professores foi o apoio da equipe de liderança, considerando, inclusive, as orientações e os esclarecimentos sobre as regras da escola. Para os docentes, o diretor da escola e o orientador pedagógico contribuem em sua inserção na carreira, orientando, auxiliando e acompanhando o trabalho desenvolvido:

“Orientação, acolhimento.” (PEF 03)

"Treinamento e esclarecimento a respeito da função, deveres e direitos antes de entrar em sala.” (PEF 25)

“Acredito que a orientação, a informação e o apoio são fundamentais." (PEF 34)

É possível inferir o quanto as orientações sobre o funcionamento da escola são importantes no início da carreira docente. Para Nono (2011, p. 166), "o ambiente organizacional influencia a carreira por meio de estilos de gestão encontrados". Por esse motivo, acredita-se que a forma como a equipe de liderança conduz a gestão da escola certamente influenciará na evolução e aquisição dos conhecimentos profissionais necessários ao exercício da profissão.

Mizukami (2010) alerta sobre a importância e necessidade que o professor tem de poder contar com o apoio e assessoria de um diretor que compreenda suas necessidades, e que, consequentemente, possa auxiliá-lo quando necessário, ajudando-o a superar seus limites e dificuldades.

\section{A IMPORTÂnCIA de PROGRAMAS DE FORMAÇÃO ESPECÍFICA PARA OS PROFESSORES INICIANTES}

Por fim, os professores participantes da pesquisa sugeriram a criação de uma formação específica aos professores iniciantes que atenda às suas necessidades e possa apoiá-los, informá-los e esclarecê-los sobre o funcionamento da unidade escolar e da rede municipal de ensino. Além de proporem que essa formação seja continuada no decorrer do estágio probatório, isto é, que durante os três primeiros anos eles recebam orientações, formação e acompanhamento pontual.

Reuniões com orientações voltadas para os iniciantes (PEF 21).

\footnotetext{
"Uma orientação inicial é muito importante para que o professor iniciante possa saber o que esperam dele." (PEF 39)

"Momentos específicos para orientações iniciais." (PEF 54)

"Fazer a integração antes de começar a trabalhar." (PEF 56)

"Formação diferenciada para novos docentes." (PEI 05)

"Grupos de discussão e estudos de casos para os professores iniciantes.” (PEI 14)

"Inserir os docentes nas formações: mestrado e doutorado.” (PEI 32)
}

Ao analisar as ações que foram sugeridas, torna-se evidente que esse é um período difícil na carreira docente, em que o professor está repleto de dúvidas, conflitos, medos e tensões; por isso, sugerem um apoio específico aos iniciantes, que atenda às necessidades desse momento tão peculiar. Gatti et al. (2011) afirmam que nesse período ocorrem as maiores taxas de evasão dos docentes, pois, ao se depararem com diversas situações nunca vividas, veem-se desamparados. Daí a necessidade de se pensar numa política de formação voltada especificamente ao início da carreira docente. Tal ação permitiria que o 
docente iniciante passasse por essa fase de inserção de forma mais segura, podendo capacitar-se para o exercício da profissão.

Gatti et al. (2011, p. 213) ressaltam ainda a necessidade de se criarem "programas de iniciação que incluam estratégias de apoio, acompanhamento e capacitação" ao professor iniciante, no intuito de "deixar o peso dessas tarefas mais leve", pois terão com quem compartilhar suas dúvidas, anseios e necessidades, serão acolhidos e receberão formação de acordo com as suas necessidades.

Alguns estudos, como os de Papi e Martins (2010), Marcelo Garcia (1999), André (2015) e Nóvoa (2006), apontam a necessidade de oferecer tratamento e apoio diferenciados aos professores iniciantes, que atendam às necessidades características dessa etapa, que os cuide e os acolha. Nóvoa (2006) alerta para o fato de que:

[...] se não formos capazes de construir formas de integração mais harmoniosas, mais coerentes desses professores, nós vamos acentuar nesses anos de profissão dinâmicas de sobrevivência individual que conduzem necessariamente a um fechamento individualista dos professores (NÓVOA, 2006, p. 14).

É preciso cultivar um ambiente colaborativo, de integração, de trocas de conhecimento e experiências. Do contrário, o professor irá se fechar em sua sala com suas dúvidas, medos e anseios, como denuncia Sarmento (1994). Para o autor, há um risco de se propiciar uma "cultura do individualismo", na qual o docente se fecha em sua sala, isola-se, fica solitário, por ver a sua aula como um momento íntimo que não pode ser observado por ninguém, o que se dá por medo e insegurança de ver suas fragilidades.

Nesse sentido, é preciso que o professor recuse a "cultura do individualismo" e, no mesmo sentido de Nóvoa (2006), construa uma cultura de cooperação, de trocas, a fim de consolidar seu conhecimento por meio da reflexão coletiva. Não basta ser reflexivo, sozinho, a formação é um fazer permanente que se refaz na ação e nas trocas, no diálogo, nos espaços de participação coletiva.

\section{CONSIDERAÇÕES FINAIS}

O início da carreira docente é um período tenso, repleto de desafios e dificuldades. Marcelo Garcia $(1999,114)$ afirma que "é característico desse período a insegurança e falta de confiança em si mesmo", uma vez que o professor iniciante se sente despreparado para assumir uma sala de aula. Com os professores participantes não foi diferente, demonstraram sentir dificuldade e insegurança no início de suas carreiras.
Por meio dos dados coletados, foi possível analisar como foi o início da carreira docente desses professores, seus sentimentos, como foram acolhidos e quais foram as condições de trabalho que encontraram.

Os professores em questão revelaram que a falta de experiência foi um fator marcante nas dificuldades experimentadas, como a dificuldade em relacionar a teoria aprendida na formação inicial à prática docente, e até mesmo o excesso de alunos na turma. Esses condicionantes causaram mal-estar, sofrimento e desconforto aos profissionais, mas também revelaram que o apoio dos colegas mais experientes e as trocas de experiências foram de grande valia no processo de inserção profissional. $\mathrm{O}$ que os ajudou na aprendizagem da docência.

Da mesma forma que apontam a necessidade do aumento salarial e da formação específica para os professores iniciantes como importantes para esse momento de grande impacto na formação docente, os professores veem as orientações por parte da equipe de gestão como fonte de aprendizagem da docência.

Os resultados possibilitaram identificar que as experiências vividas por eles se converteram em sugestões de medidas que poderão contribuir para o aprimoramento da prática docente e para a inserção de professores iniciantes na carreira. Além de auxiliar no planejamento de ações formativas específicas para essa etapa, como momentos sistematizados de orientação e trocas de experiências, a saber:

- oportunizar apoio, integração, formação e acompanhamento a todos os professores iniciantes, via Secretarias de Educação;

- propiciar ao professor iniciante uma acolhida, com recepção e integração (regras e sistema de ensino) à escola, comandada pela equipe gestora;

- oferecer formação e acompanhamento específico aos professores iniciantes que atendam às suas necessidades, e que essa formação seja prevista em edital para que saibam que ao longo do estágio probatório (três anos) participarão de formação e acompanhamento. Podendo estes ocorrer em centros formadores específicos para isso, de forma regular, uma vez ou duas vezes na semana, para aprender, trocar experiências e expor suas dúvidas;

- assegurar que os conteúdos da formação sejam compostos por saberes da prática, isto é, úteis à prática da sala de aula;

- planejar e oportunizar momentos de estudo sobre a organização curricular das Secretarias de Educação;

- colocar um professor mais experiente como mentor do professor iniciante; 
- garantir espaço para trocas de experiências entre os pares nos horários de trabalho coletivo.

- oportunizar que o professor iniciante possa ingressar numa escola mais favorável, para evitar o início da carreira em contextos problemáticos.

Nesse sentido, conhecer o que dizem e percebem os professores que se iniciam na carreira indica possibilidades de ação em termos de políticas públicas para que a inserção dos docentes na profissão seja intencionalmente planejada pelas instituições de ensino. E para que esse momento da carreira seja compreendido como de fundamental importância para o desenvolvimento profissional docente e para a qualidade dos processos de ensino.

\section{REFERÊNCIAS}

ANDRÉ, Marli. Políticas e programas de apoio aos professores iniciantes no Brasil. Cadernos de Pesquisa, v. 42, n. 145, p. 112-129, jan./abr. 2012.

ANDRÉ, Marli. Políticas de formação continuada e de inserção à docência no Brasil. Educação Unisinos, v. 19, n. 1, p. 34-44, jan.-abr. 2015.

CHIZZOTTI, Antonio. O cotidiano e as pesquisas em educação. In: FAZENDA, I. C. A. (Org.). Novos enfoques da pesquisa educacional, 7. ed. São Paulo: Cortez: 2010.

FREIRE. Paulo. Pedagogia da autonomia: saberes necessários à prática docente. São Paulo: Paz e Terra, 1997.

FREIRE. Paulo. A educação na cidade. São Paulo: Cortez, 2001.

GATTI, Bernadete Angelina; BARRETO, Elba Siqueira de Sá; ANDRÉ, Marli Eliza Dalmazo de Afonso. Políticas docentes no Brasil: um estado da arte. Brasília, DF: Unesco, 2011.
HUBERMAN, Michael. O ciclo de vida profissional dos professores. In: NÓVOA. A. (Org.). Vidas de professores. Portugal: Porto Editora, 1995. p.31-61.

LIMA, Emília Freitas de. Sobrevivência no início docência. Brasília: Líber Livro Editora, 2006.

MARCELO GARCIA, Carlos. Formação de professores: para uma mudança educativa. Porto: Porto Editora, 1999.

MARCELO GARCIA, Carlos; VAILLANT, Denise. Desarollo profesional docente: como se aprende a enseñar? Madrid: Narcea, 2009.

MIZUKAMI, Maria da Graça Nicoletti. Escola e aprendizagem da docência: processos de investigação e formação. São Carlos: Edufscar, 2010.

NONO, Maévi Anabel. Professores iniciantes: o papel da escola em sua formação. Porto Alegre: Mediação, 2011.

NÓVOA, Antonio. Desafios do trabalho do professor no mundo contemporâneo: nada substitui o trabalho do professor. Palestra. Sinpro, SP, 2006. Disponível em: <http://www.sinprosp.org.br/ arquivos/novoa/livreto_novoa.pdf $>$. Acesso em: 25 maio 2015.

PAPI, Silmara de Oliveira Gomes; MARTINS, Pura Lúcia Oliver. As pesquisas sobre professores iniciantes: algumas aproximações. Educação em Revista, Belo Horizonte, v. 26, n. 3, p. 39-56, dez. 2010.

PERRENOUD, Philippe. Ensinar na urgência, decidir na incerteza: saberes e competências em uma profissão complexa. Porto Alegre: Artmed, 2001.

SARMENTO, Manuel Jacinto. A vez e a voz dos professores. Porto: Porto Editora, 1994.

Recebido em 21-12-2016. Aprovado em 30-05-2017. 